\title{
Studies on Biosynthetic Genes and Enzymes of Isoprenoids Produced by Actinomycetes
}

\author{
Tohru Dairi
}

Received: January 19, 2005 / Accepted: March 25, 2005

(C) Japan Antibiotics Research Association

\begin{abstract}
Most Streptomyces strains are equipped with only the 2-C-methyl-D-erythritol 4-phosphate (MEP) pathway for the formation of isopentenyl diphosphate, a common precursor of isoprenoids. In addition to this pathway, some Streptomyces strains possess the mevalonate (MV) pathway via which isoprenoid antibiotics are produced. We have recently cloned and analyzed the MV pathway gene clusters and their flanking regions from terpentecin, BE-40644, and furaquinocin A producers. All these clusters contained genes coding for mevalonate kinase, mevalonate diphosphate decarboxylase, phosphomevalonate kinase, type 2 IPP isomerase, HMGCoA reductase, and HMG-CoA synthase. The order of each of the open reading frames (ORFs) is also the same, and the respective homologous ORFs show more than $70 \%$ amino acid identity with each other. In contrast to these conservative gene organizations, the biosynthetic genes of terpentecin, BE-40644, and furaquinocin A were located just upstream and/or downstream of the MV pathway gene cluster. These facts suggested that all the actinomycete strains possessing both the MV and MEP pathways produce isoprenoid compounds and the biosynthetic genes of one of these isoprenoids usually exist adjacent to the MV pathway gene cluster. Therefore, when the presence of the MV cluster is detected by molecular genetic techniques, isoprenoids may be produced by the cultivation of these actinomycete strains. During the course of these studies, we identified diterpene cyclases possessing unique primary structures that differ from those of eukaryotes and catalyze unique reactions.
\end{abstract}

T. Dairi: Biotechnology Research Center, Toyama Prefectural University, 5180 Kurokawa, Kosugi-machi, Toyama 939-0398, Japan, E-mail: dairi@pu-toyama.ac.jp
Keywords isoprenoid, mevalonate pathway, biosynthesis, cyclase, Actinomycetes

\section{Introduction}

Actinomycete strains usually produce a number of secondary metabolites that often possess pharmaceutical activities. Therefore, for a long time, the strains have been used for many screenings to find novel, medically useful compounds. Consequently, more than 60 percent of the known antibiotics, including not only antibacterial antibiotics but also bioactive microbial compounds, have been reported to be produced by actinomycetes [1]. Presently, such pharmaceutically important, novel compounds can be found in the culture broth of actinomycete strains by screening rare actinomycetes, developing new screening strategies, employing sensitive assay methods for the detection of low concentrations of antibiotics, etc. However, sometimes, "semi-new antibiotics"-derivatives of known antibiotics-were isolated; discovering novel antibiotics every year became very difficult.

In the past two decades, recombinant DNA technology has come into play in this field. Gene clusters encoding many natural products have been cloned and characterized. Moreover, whole-genome sequencing has uncovered hundreds of candidates for secondary metabolic pathways. Among them, the biosynthetic machinery of nonribosomal peptide and polyketide natural products has been extensively investigated [2 7]. Recent progress in the application of combinatorial biosynthesis methods to these biosynthetic pathways revealed the possibilities of expanding the repertoire of the various types of these useful 
compounds.

In contrast to nonribosomal peptide and polyketide natural products, the biosynthetic machinery of isoprenoids, which form the largest single family of compounds found in nature with over 24,000 known examples [8,9] and contain industrially useful compounds such as flavors, antibiotics, and plant hormones, still remains unclear. Only limited examples of isoprenoid biosynthetic genes have been cloned from mainly plants and fungi, probably because isoprenoid biosynthetic enzymes of plants are usually membrane bound, resulting in technical difficulties while purifying such enzymes from natural resources and while expressing recombinant enzymes in E. coli. Moreover, scattering of biosynthetic genes on genomic DNA also makes it difficult to clone all the biosynthetic genes.

On the other hand, actinomycete strains produce several isoprenoid compounds such as 2-methylisoborneol, geosmin, squalene-hopene etc., and frontier studies on pentalenene synthase, a sesquiterpene synthase from an actinomycete strain, demonstrated that the enzyme is not membrane-bound and is expressed with relative ease as a recombinant enzyme in E. coli [10]. This enabled us to investigate the properties of biosynthetic enzymes in detail. Moreover, it was recently revealed that, actinomycetes produce relatively large number of many types of isoprenoids among prokaryotes and the structures of these compounds are unique and different from those of eukaryotic origin [11 18]. These facts suggest that isoprenoid compounds produced by actinomycetes would be potent lead compounds for drug discovery. Therefore, effective screening methods are essential for the selection of actinomycetes that produce isoprenoids because the number of isoprenoid producers is reported to be extremely small when compared with that of nonribosomal peptide and polyketide producers [1]. Recent developments in the enzymology and genetics of isoprenoid biosynthesis in actinomycetes enabled us to develop a methodology for detecting isoprenoid-antibiotic producers among actinomycetes by using techniques of molecular biology. This report reviews the studies that laid the groundwork for the formulation of this strategy.

We also focused on the biosynthetic genes and enzymes of isoprenoids produced by actinomycetes. Since there are few reports regarding isoprenoid biosynthetic genes and enzymes of prokaryotic origin, this review will mainly focus on our recent studies.

\section{Biosynthesis of Isoprenoids}

Although excellent reviews focusing on biosyntheses of isoprenoids have been published [8,9], the process is briefly described for a better understanding of this report. All isoprenoid compounds are derived from their fivecarbon precursors, isopentenyl diphosphates (IPP). In eukaryotes and archaebacteria, the mevalonate (MV) pathway concerned with the formation of IPP is well established [8, 9] (Fig. 1). However, it has recently been revealed that IPP is synthesized via the 2-C-methyl-Derythritol 4-phosphate (MEP) pathway in most bacteria, green algae, and in the chloroplasts of higher plants [19] (Fig. 1).

The first step in isoprenoid biosynthesis is catalyzed by polyprenyl diphosphate synthase (PDS) that sequentially condenses IPP into allylic diphosphates, such as dimethylallyl diphosphate (DMAPP), to produce linear polyprenyl diphosphates with specific chain lengths. Geranyl diphosphate (GDP) synthase, farnesyl diphosphate (FDP) synthase, and geranylgeranyl diphosphate (GGDP) synthase catalyze the additions of one, two, and three molecules of IPP to DMAPP, yielding GDP $\left(\mathrm{C}_{10}\right)$, FDP $\left(\mathrm{C}_{15}\right)$, and GGDP $\left(\mathrm{C}_{20}\right)$, respectively (Fig. 2). In many cases, these polyprenyl diphosphates undergo a range of cyclizations to produce the parent skeletons of monoterpenes $\left(\mathrm{C}_{10}\right)$, sesquiterpenes $\left(\mathrm{C}_{15}\right)$, and diterpenes $\left(\mathrm{C}_{20}\right)$ (Fig. 3), followed by a variety of modifications, such as hydroxylation, methylation, and glycosylation, etc., to give rise to thousands of different isoprenoid metabolites. Therefore, the first key enzymes leading to the diversity of isoprenoids are isoprenoid cyclases.

Isoprenoid cyclases are classified into two major types based on their modes of cyclization [9, 20]. One type of cyclization (Fig. 3, type A) is initiated by the ionization of polyprenyl diphosphates, such as GDP, FDP, and GGDP, with chain lengths of $\mathrm{C}_{20}$ or less, to an allylic carbocation, followed by cyclization and deprotonation to the olefin. The other type of cyclization (Fig. 3, type B) is initiated by protonation at the terminal-double bond of polyprenyl diphosphates, such as GGDP and (oxido)squalene $\left(\mathrm{C}_{30}\right)$, with chain lengths of $\mathrm{C}_{20}$ or more. The former and the latter class of enzymes are known to possess a DDXXD motif and a DXDD motif, respectively, which mediate substrate binding by chelation of a divalent metal ion. In both the cases, successive reactions, such as hydride shift and methyl transfer, continue until carbocation is quenched in a manner that is specific to each cyclase.

Until now, more than 50 isoprenoid cyclase genes have been cloned from eukaryotes, and a few isoprenoid cyclase 
(A)



D-Glyceraldehyde

$\underset{\substack{\text { CyEP } \\ \text { transferase }}}{(\text { CDP-ME }} \underset{\text { OH }}{\text { CTP }}$

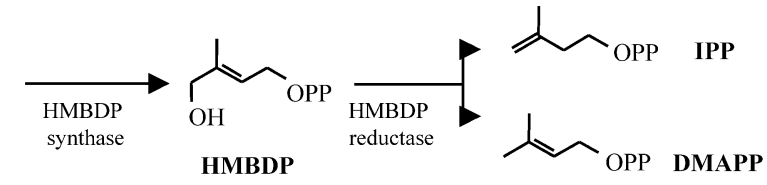

(B)
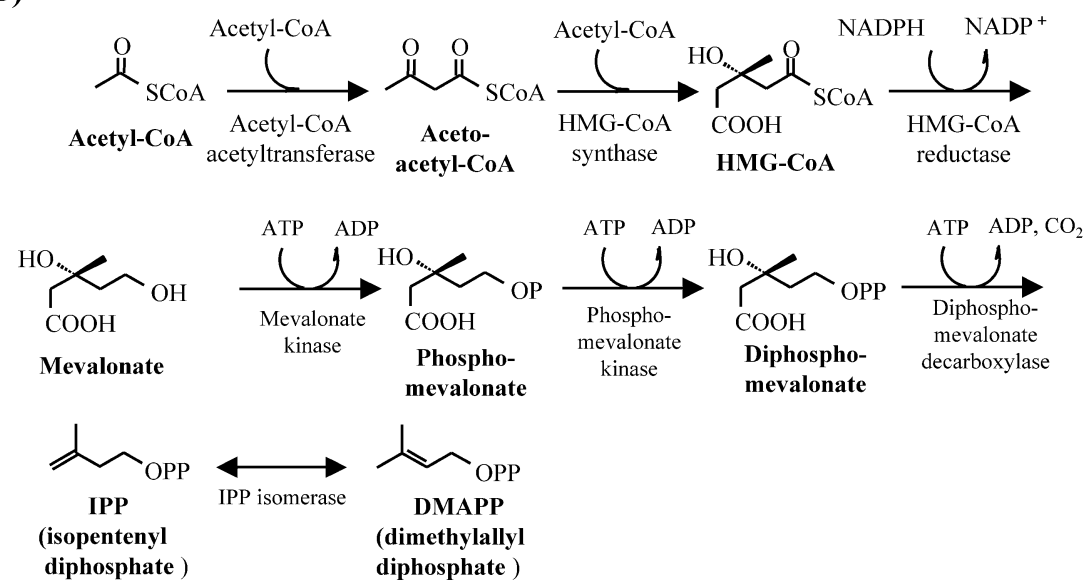

Fig. 1 2-C-methyl-D-erythritol 4-phosphate (MEP) pathway (A) and mevalonate pathway (B).

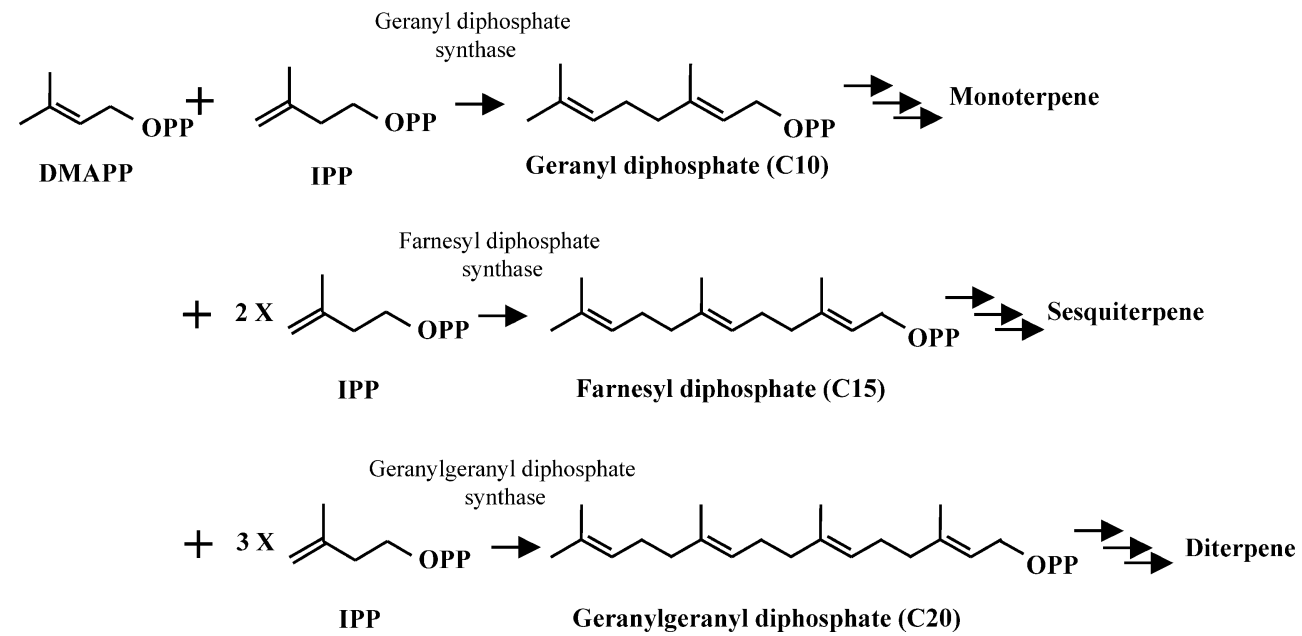

Fig. 2 The first stage of isoprenoid biosynthesis catalyzed by polyprenyl diphosphate synthase. 


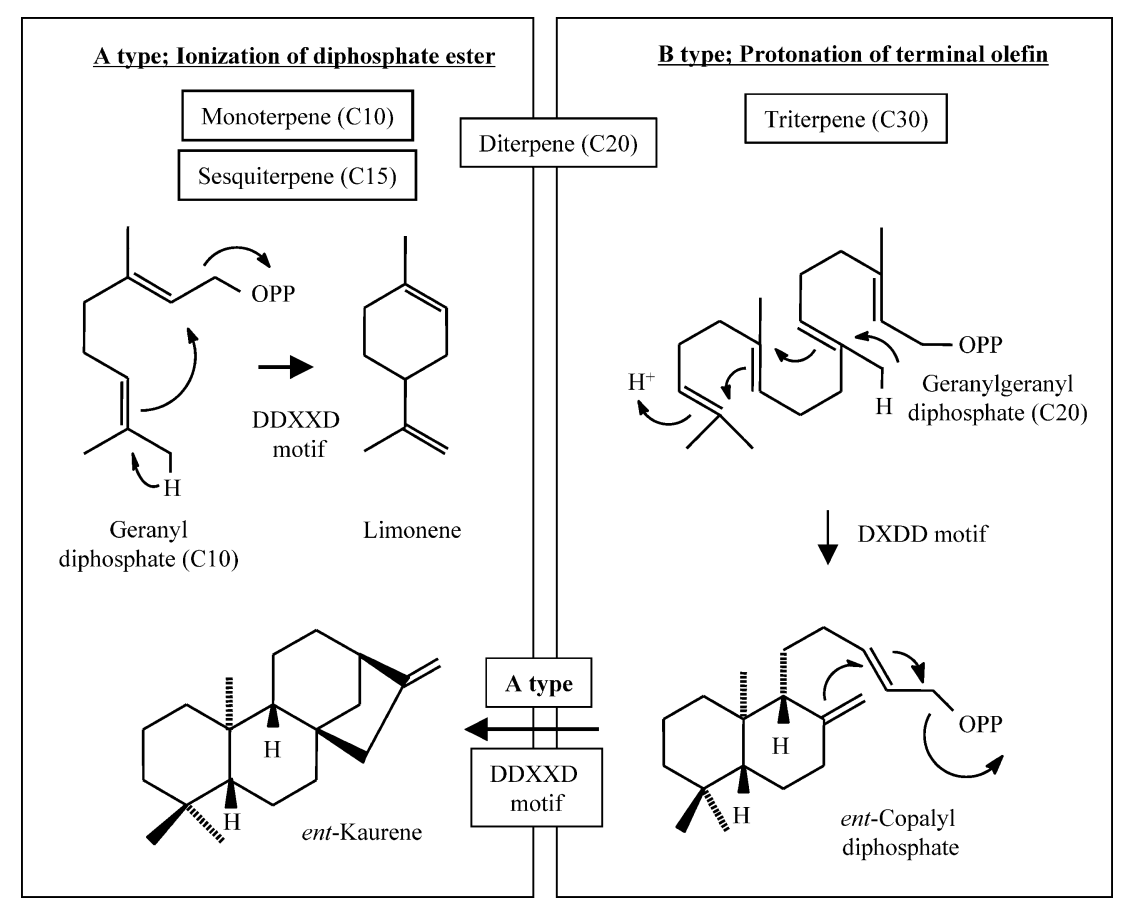

Fig. 3 Two types of cyclization mechanisms of polyprenyl diphosphates. A type of cyclization and B type of cyclization are initiated by elimination of diphosphate and protonation of terminal double bound, respectively. The former type is responsible for monoterpene $\left(C_{10}\right)$ and sesquiterpene $\left(C_{15}\right)$ biosynthesis. (Oxido) squalene $\left(C_{30}\right)$ biosynthesis is catalyzed by the latter type of cyclases. Interestingly, both types are known to participate in diterpene $\left(C_{20}\right)$ biosynthesis, exemplified by ent-kaurene biosynthesis.

genes have been cloned from the prokaryotes. The cyclization mechanisms of their products were studied using recombinant enzymes. (Oxido)squalene cyclases $\left(\mathrm{C}_{30}\right)$ from both eukaryotes and prokaryotes are representatives [21 24]. Other than triterpene $\left(\mathrm{C}_{30}\right)$ cyclases, Croteau and co-workers extensively studied reaction mechanisms of enzymes, such as $(-)$-limonene synthase $\left(\mathrm{C}_{10}\right)$ [25], myrcene synthase $\left(\mathrm{C}_{10}\right)$ [25] (-)pinene synthase $\left(\mathrm{C}_{10}\right)$ [25], (-)-camphene synthase $\left(\mathrm{C}_{10}\right)$ [26], (-)-beta-phellandrene synthase $\left(\mathrm{C}_{10}\right)$ [26], terpinolene synthase $\left(\mathrm{C}_{10}\right)$ [26], delta-selinene synthase $\left(\mathrm{C}_{15}\right)$ [27], gamma-humulene synthase $\left(\mathrm{C}_{15}\right)$ [27], bisabolene synthase $\left(\mathrm{C}_{15}\right)$ [28], and abietadiene synthase $\left(C_{20}\right)$ [29], etc., from grand fir (Abies grandis). Croteau et al. [30] cloned and characterized a gene encoding taxadiene synthase $\left(\mathrm{C}_{20}\right)$ that catalyzes the committed step of biosynthesis of taxol, an anticancer drug isolated from yew.

Besides Abies grandis, dozens of isoprenoid cyclase genes have been cloned from plants such as castor bean [31] Norway spruce [32, 33], maize [34 36], pine [37], ginkgo [38], snapdragon [39], grapevine [40], lotus [41], and tobacco [42]; some of these genes were isolated to investigate the relationship between isoprenoid production and their defensive effects against potential herbivores and pathogens at the molecular genetic level. Moreover, it was proved that among putative isoprenoid synthase genes discovered by whole genome sequence analysis and in silico analysis in Arabidopsis thaliana, at least six genes, namely, At3g25810, At1g61680, At4g16740, At2g24210, At3g25820, and At3g25830, encoded monoterpene synthases [43 46]. Diterpene cyclases responsible for the biosynthesis of gibberellin, a plant hormone, in plants and fungi have also been studied in detail [47 51]. Furthermore, diterpene cyclases participating in the biosyntheses of phytoalexins in rice have been reported very recently [52 58]. As for lower eukaryotes, several unique isoprenoid cyclase genes, such as aristolochene synthase gene [59], aphidicolan-16 beta-ol synthase gene [60], and ent-kaurene synthase gene [49, 61], were cloned and characterized. Fungi, in particular, were found to possess bi-functional diterpene cyclases that can convert geranylgeranyl diphosphate into ent-kaurene [49, 61]. In contrast, in plants, ent-kaurene is synthesized from geranylgeranyl diphosphate via copalyl diphosphate in a two-step cyclization that is catalyzed by two distinct enzymes, copalyl diphosphate synthase [47] and entkaurene synthase [48] (Fig. 3). In contrast to these 
(A)
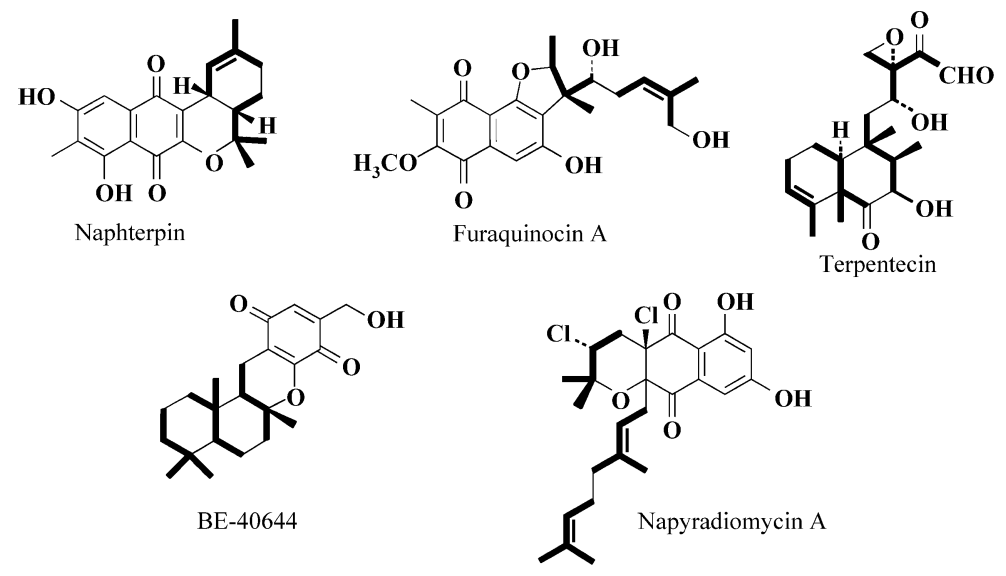

(B)
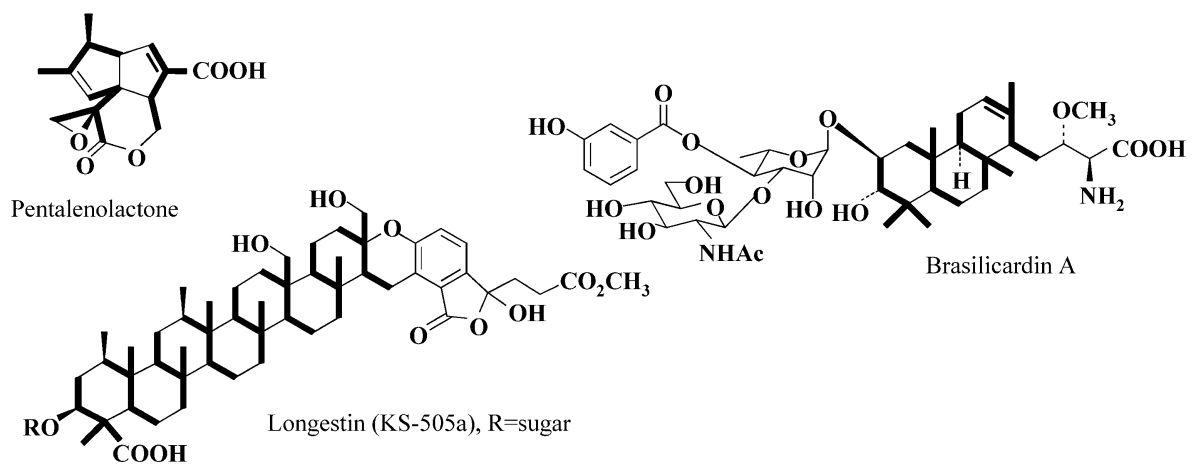

Fig. 4 Structures of isoprenoids produced by actinomycetes. Isoprene units, which are biosynthesized via the mevalonate pathway $(A)$ and the MEP pathway $(B)$, are highlighted by bold lines.

eukaryotic isoprenoid cyclases, only limited studies on prokaryotic isoprenoid cyclases have been reported so far $[10,62]$. Therefore, studies were conducted to investigate the biosynthetic genes and enzymes of isoprenoid antibiotics produced by actinomycetes, particularly focusing on the cloning and characterization of the genes of the mevalonate pathway and the genes of isoprenoid cyclase.

\section{Cloning and Analysis of a Mevalonate Pathway} Gene Cluster from a Terpentecin (TP) Producer

Although most Streptomyces strains, which are prokaryotic, possess only the MEP pathway for the formation of IPP, it was previously clarified that both the MV and MEP pathways were operating in some Streptomyces strains such as Kitasatospora griseola (TP producer) [63], Actinoplanes sp. strain A40644 (BE-40644 producer) [64], Streptomyces sp. strain CL190 (naphterpin producer) [65], Streptomyces sp. strain KO-3988 (furaquinocin producer) [66], and Chainia rubra (napyradiomycin producer) [67] (Fig. 4A). Interestingly, it was proved that these strains produced isoprenoid compounds mainly via the MV pathway
[63 67]. These facts suggest that the presence of the MV pathway is closely related to the production of isoprenoid compounds in actinomycetes. In contrast, some actinomycetes possessing only the MEP pathway, such as Streptomyces sp. strain UC5319, Nocardia brasiliensis, and Streptomyces argenteolus, also produce the isoprenoid compounds, pentalenolactone [68], brasilicardin A [69], and KS-505a [70], respectively (Fig. 4B). These facts show that the presence of the MV pathway is not essential for the production of isoprenoids in actinomycetes. Therefore, in order to clearly understand the biological significance of the presence of the MV pathway in actinomycetes, we have sought to clone the mevalonate pathway gene clusters and isoprenoid biosynthetic gene clusters from actinomycetes.

Kitasatospora griseola, a diterpene antibiotic terpentecin (TP, Fig. 4A) producer, was selected as the target because we also wanted to clone a diterpene cyclase gene responsible for the biosynthesis of TP in addition to the MV pathway genes was essential. Since TP possesses antibacterial activity [12] and has been shown to be mainly synthesized via the MV pathway [63], we expected that the MV pathway defective mutants would be present in TP non-producers, which could be easily detected by a bioassay. By treating the spores of the TP producer with a 
(A)

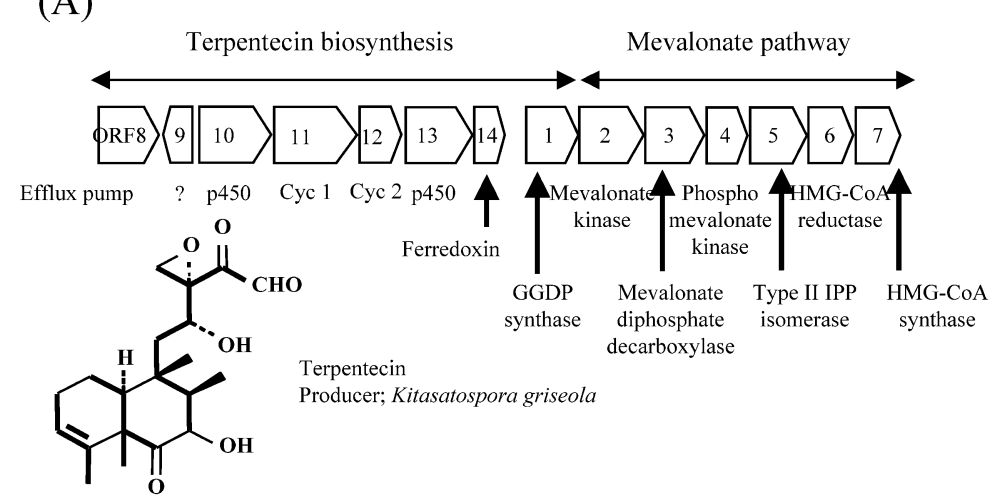

(B)

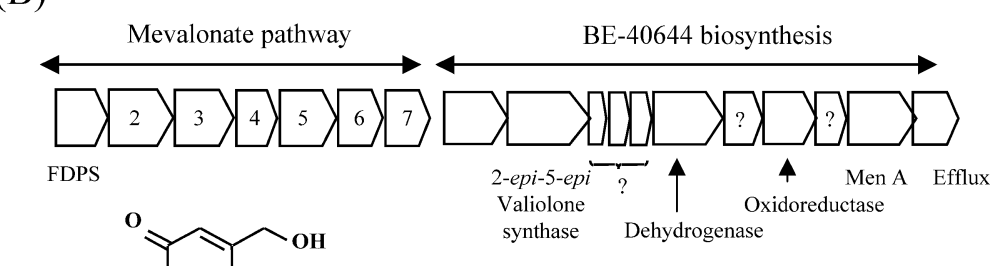<smiles>CC12CCC3C(C)(C)CCCC3(C)C(=C(C(=O)CO)C(=O)C=C1CO)O2</smiles>

BE-40644

Producer; Actinoplanes sp. A40644

(C)

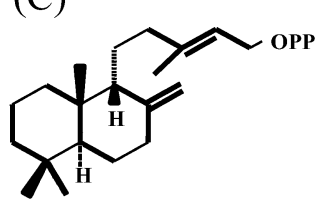

Copalyl diphosphate

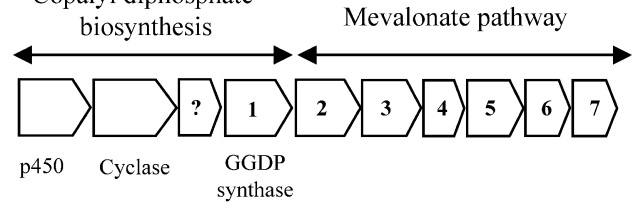

ent-Copalyl diphosphate

Producer; Streptomyces sp. KO3988

Fig. 5 Mevalonate pathway gene clusters and their flanking regions in terpentecin (A), BE-40644 (B), and furaquinocin A (C) producers.

mutagen, we isolated a mutant lacking an HMG-CoA reductase activity as expected [71]. By a shotgun cloning experiment using the mutant as a host, a DNA fragment that restored both TP productivity and HMG-CoA reductase activity was obtained. The nucleotide sequence of the fragment revealed a single complete ORF that had a significant similarity to an HMG-CoA reductase of Streptomyces sp. CL190 (an isoprenoid, naphterpin producer), which has been cloned by using a reverse genetic method for the first time from eubacterial origin (89\% identity) by Takahashi et al. [72]. Moreover, the gene product was also similar to HMG-CoA reductases from a variety of organisms, including sea urchin (40.3\%), German cockroach (37.6\%), and camptotheca (39.7\%).

In Streptomyces sp. CL190, mevalonate kinase (MK), mevalonate diphosphate decarboxylase (MDPD), phosphomevalonate kinase (PMK), Type 2 IPP isomerase, HMG-CoA reductase, and HMG-CoA synthase genes were reported to be clustered in the order mentioned above [73]. Therefore, the flanking regions of the HMG-CoA reductase gene cloned from the TP producer were also analyzed in order to investigate whether other MV pathway genes existed in a manner similar to that in strain CL190. Finally, we identified genes similar to those found in the strain CL190, in the same order [74]. However, in the TP producer, a GGDP $\left(\mathrm{C}_{20}\right)$ synthase gene was located just upstream of the MV pathway gene cluster [74] (Fig. 5A).

The MV pathway gene cluster thus obtained was confirmed to encode the predicted enzymes by heterologous expression in S. lividans and E. coli [74], which utilize only the MEP pathway for the formation of IPP. Moreover, the ORF2 and the ORF4 (Fig. 5A) were expressed as recombinant enzymes in $E$. coli, and an in vitro assay was performed because both the ORFs showed significant similarities to MK [74]. Considering the established MV pathway, one would be an MK, while the 
other would be a PMK, respectively. Consequently, we confirmed that the ORF2 and the ORF4 were MK and PMK, respectively.

TP Biosynthetic Gene Cluster Exists in the Region Upstream of the MV Pathway Cluster

Considering that antibiotic biosynthetic genes cloned from actinomycetes are usually clustered in the genomic DNA region and that GGDP synthase, which supplies a direct precursor of TP biosynthesis, existed in the region just upstream of the MV pathway cluster, the TP biosynthetic genes were also expected to exist in the region further upstream of the GGDP synthase gene. To examine this possibility, the DNA sequence of that region was determined. Frame analysis of the DNA sequence showed 7 ORFs (ORF8 14) in the same direction, except for ORF9 (Fig. 5A). Each of the ORFs had a significant similarity to efflux proteins responsible for antibiotic resistance (ORF8), an unknown protein found in the genomic DNA of Streptomyces coelicolor A3(2) (ORF9), P450 (ORF10), diterpene cyclase from eukaryote (Cyc1), a pentalenene synthase of Streptomyces strain (Cyc2), P450 (ORF13), and ferredoxin (ORF14), respectively [75]. Considering that TP was previously reported to be synthesized from GGDP after successive cyclization, hydroxylation, and epoxidation, these ORFs were believed to encode TP biosynthetic genes. To confirm this probability, gene disruption experiments were employed [75]. We constructed two types of mutants in which $c y c 1$ or $c y c 2$ was inactivated by a gene replacement technique and confirmed that either of the mutants did not produce TP, showing that both cyc1 and cyc2 were essential for the production of TP.

\section{Detailed Analysis of Cyc1 and the Cyc2}

\section{Function of Cyc1 and Cyc2}

Considering that both the $\mathrm{Cyc} 1$ and $\mathrm{Cyc} 2$ products were essential for the production of TP (4) and had significant similarities to isoprenoid cyclases, these proteins were expected to catalyze the cyclization of GGDP (1). To confirm this possibility and to elucidate the structure of a reaction product formed by these enzymes, $c y c 1$ and $c y c 2$ genes were heterologously expressed in S. lividans TK23, and the production of new metabolites in the culture broth of the transformant was investigated. Finally, a novel compound was detected; it was designated as terpentetriene (Fig. 6, TTE, 3), based on the structural similarities to TP (4) and the presence of three double bonds, in the culture broth of the transformant. To verify the enzymatic functions of $\mathrm{Cyc} 1$ and $\mathrm{Cyc} 2$, these ORF products were overproduced as His-tagged fusion proteins in E. coli and were used for an enzyme assay. Incubation of both the recombinant proteins with GGDP (1) resulted in the formation of TTE (3), confirming that the Cyc1 and Cyc2 products were the diterpene cyclases essential for the formation of TP (4) [75].

Next, we investigated the enzymatic properties of $\mathrm{Cyc} 1$ and Cyc2. First, we examined whether Cyc1 and Cyc2 had no interaction with each other or formed a heterodimer because an intermediate, which was formed from GGDP (1) and converted into TTE (3), might have been detected in the former case. The assay mixture containing the recombinant $\mathrm{Cyc} 1$ and $\mathrm{Cyc} 2$ was subjected to gel filtration. No peaks corresponding to the heterodimer were eluted, thereby suggesting that they had no interaction with each other. Therefore, we searched for an intermediate that was converted from GGDP (1) by Cyc1 or Cyc2.

Cyc1 was incubated with GGDP (1); it was subsequently inactivated by boiling, and the enzyme reaction was then continued by adding Cyc2 into the reaction mixture. Under this reaction condition, the formation of TTE (3) was confirmed [76]. On the other hand, TTE (3) was not formed by the enzyme reaction in which Cyc2 was used first, followed by inactivation and the addition of Cyc1. These results suggest that $\mathrm{Cyc1}$ formed an intermediate from GGDP (1). Considering that Cyc1 is similar to the isoprenoid cyclases with DXDD motifs, it was hypothized that Cyc1 converted GGDP (1) into a cyclized intermediate with the diphosphate group by the protonation-initiated cyclization (Fig. 3, B type). To detect a compound formed from GGDP (1) by Cyc1, GGDP (1) was incubated with the purified $\mathrm{Cyc1}$, and the reaction mixture was analyzed by reversed-phase HPLC by using an ion-pair reagent. Consequently, a new product was specifically detected in the reaction mixture. The product was purified, and its structure was determined as shown in Fig. 6. We named this new product as terpentedienol diphosphate (TDP, 2), based on structural similarities to TTE (3) and the presence of two double bonds and a diphosphate. We also confirmed that TDP (2) was converted into TTE (3) by Cyc2, showing that TDP (2) is the real intermediate converted from GGDP (1) by Cyc1 [76].

\section{Enzymatic Properties of Cyc1 and Cyc2 [76]}

In a manner similar to many isoprenoid cyclases analyzed so far, Cyc1 required $\mathrm{Mg}^{2+}$ as a catalyst. No activity was detected with other divalent metal ions, such as $\mathrm{Ca}^{2+}, \mathrm{Co}^{2+}$, $\mathrm{Cu}^{2+}, \mathrm{Fe}^{2+}, \mathrm{Mn}^{2+}$, and $\mathrm{Zn}^{2+}$. Cyc1 showed a high activity around neutral $\mathrm{pH}$, while maximum activity was observed 


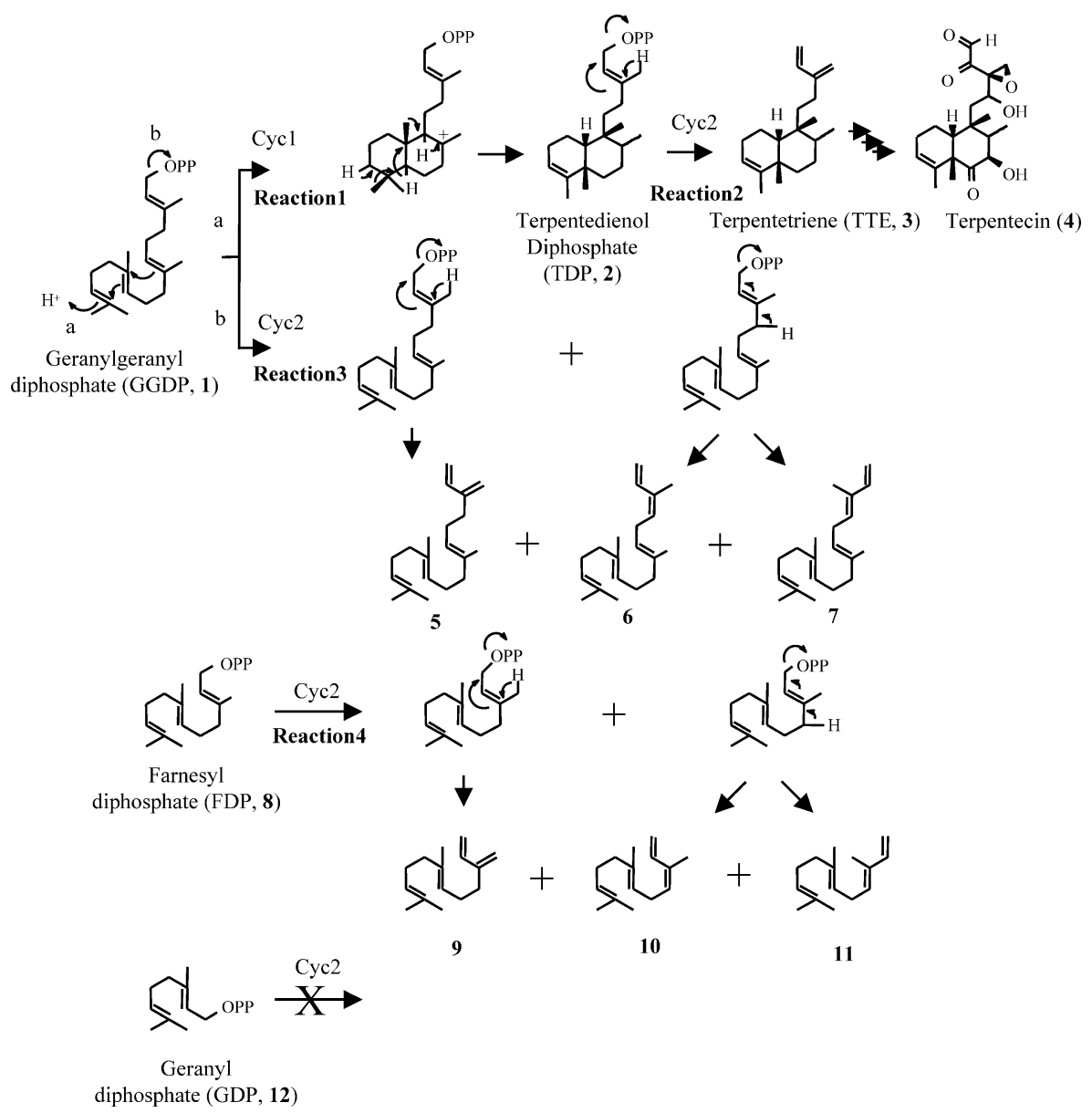

Fig. 6 Summary of the enzymatic reactions catalyzed by the Cyc1 and the Cyc2. Numbers indicate the following compounds: 1, GGDP; 2, TDP; 3, TTE; 4, TP; 5, 1,3(20),6,10,14-phytapentaene; 6, $\alpha$-springene; 7, 3,7,11,15tetramethylhexadeca-1,3,6,10,14-pentaene $(E, E, E) ; \mathbf{8}$, farnesyl diphosphate; 9, 7,11-dimethyl-3-methylenedodeca-1,6,10triene $(E) ; \mathbf{1 0}, 3,7,11$-trimethyldodeca-1,3,6,10-tetraene $(Z, E) ; \mathbf{1 1}, 3,7,11$-trimethyldodeca-1,3,6,10-tetraene $(E, E) ; \mathbf{1 2}$, geranyl diphosphate.

at $\mathrm{pH} 6.8$ (Tris- $\mathrm{HCl}$ ); it was rapidly lost with either a decrease or an increase in $\mathrm{pH}$. The enzyme activity was maximal at $25^{\circ} \mathrm{C} \sim 30^{\circ} \mathrm{C}$ and was not detected at above $50^{\circ} \mathrm{C}$. Cyc1 retained full activity after incubation at $30^{\circ} \mathrm{C}$ in $0.05 \mathrm{M}$ Tris- $\mathrm{HCl}$ buffer at $\mathrm{pH} 6.8$ for 1 hour. Under the optimal $\mathrm{pH}$ and temperature conditions, $20 \%$ glycerol, $5 \mathrm{mM} 2$-mercaptoethanol, and $0.1 \%$ Tween 80 were found to enhance the activity of $\mathrm{Cyc} 1$.

The kinetic properties of Cycl were studied under optimal reaction conditions. The $K \mathrm{~m}$ value and $V \max$ value were calculated to be $64.2 \pm 5.7 \mu \mathrm{M}$ for GGDP (1) and $94.7 \pm 6.9 \mathrm{U} / \mathrm{mg}$, respectively (Table 1). The enzyme activity was inhibited by GGDP (1) at a concentration of more than $50 \mu \mathrm{M}$, as reported for other isoprenoid cyclases.

Cyc2 necessarily required $\mathrm{Mg}^{2+}$ for its activity, and the optimal concentration of $\mathrm{Mg}^{2+}$ was $1 \mathrm{mM}$. Enzyme activity was also detected with $1 \mathrm{mM}$ of $\mathrm{Mn}^{2+}, \mathrm{Fe}^{2+}$, and $\mathrm{Co}^{2+}$. No activity was detected with other divalent metal ions such as
$\mathrm{Ca}^{2+}, \mathrm{Cu}^{2+}$, and $\mathrm{Zn}^{2+}$. The optimum $\mathrm{pH}$ and temperature were 6.8 and $50^{\circ} \mathrm{C}$, respectively. Cyc2 was stable following incubation at $30^{\circ} \mathrm{C}$ in $0.05 \mathrm{M}$ Tris- $\mathrm{HCl}$ buffer at $\mathrm{pH} 6.8$ for 1 hour. For maximum activity, the additives that enhanced the activity of Cyc1 were necessary.

\section{The Cyc2 Reacted Even with GGDP (1) and Farnesyl Diphosphate (FDP, 8) [76]}

As described above, both Cyc1 and Cyc2 had an optimum $\mathrm{pH}$ of 6.8. When GGDP (1) was incubated with both Cyc1 and $\mathrm{Cyc} 2$ at $\mathrm{pH} 7.5$, at which $\mathrm{Cyc} 1$ and $\mathrm{Cyc} 2$ showed weak activity and high activity, respectively, at least two unknown products were dominantly formed as compared with TTE in the reaction mixture. By detailed analyses, it was discovered that the formation of these products completely depended on the presence of both Cyc2 and GGDP (1), thereby suggesting that Cyc2 catalyzed not only the conversion of TDP (2) into TTE (3) but also the 
Table 1 Enzymatic properties of the Cyc1 and the Cyc2

\begin{tabular}{|c|c|c|c|c|c|c|c|c|}
\hline \multirow[b]{2}{*}{ Reaction } & \multirow[b]{2}{*}{ Enzyme } & \multirow[b]{2}{*}{ Substrate } & \multicolumn{2}{|c|}{ Optimum } & \multirow[b]{2}{*}{ Metal } & \multicolumn{3}{|c|}{ pH 8.0} \\
\hline & & & $\mathrm{pH}$ & $\begin{array}{c}\text { Temp. } \\
\left({ }^{\circ} \mathrm{C}\right)\end{array}$ & & $\begin{array}{c}K \mathrm{~m} \\
(\mu \mathrm{M})\end{array}$ & $\begin{array}{c}V \max \\
(\mathrm{U} / \mathrm{mg})^{*}\end{array}$ & $\begin{array}{l}V \max / K m \\
(\mathrm{U} / \mathrm{mg} / \mu \mathrm{M})\end{array}$ \\
\hline 1 & Сyc1 & GGDP & 6.8 & 25 & $\mathrm{Mg}^{2+}$ & $\begin{array}{l}64.2 \pm 5.7 \\
\text { (at } \mathrm{pH} 6.8 \text { ) }\end{array}$ & $\begin{array}{r}94.7 \pm 6.9 \\
\text { (at } \mathrm{pH} 6.8 \text { ) }\end{array}$ & 1.48 \\
\hline 2 & Cyc2 & TDP & 6.8 & 50 & $\mathrm{Mg}^{2+}>\mathrm{Mn}^{2+}>\mathrm{Fe}^{2+}>\mathrm{Co}^{2+}$ & $7.6 \pm 0.6$ & $114.6 \pm 2.8$ & 15.08 \\
\hline 3 & Cyc2 & GGDP & 8.0 & 50 & $\mathrm{Mg}^{2+}>\mathrm{Fe}^{2+}>\mathrm{Mn}^{2+}$ & $7.9 \pm 0.6$ & $8.8 \pm 0.2$ & 1.11 \\
\hline 4 & Cyс 2 & FDP & 8.0 & 50 & $\mathrm{Mg}^{2+}>\mathrm{Fe}^{2+}>\mathrm{Mn}^{2+}$ & $61.7 \pm 3.0$ & $15.9 \pm 0.6$ & 0.26 \\
\hline
\end{tabular}

* $U=$ nmol production/min.

conversion of GGDP (1) to the unknown compounds. By GC-MS and NMR analyses, the compounds were determined to be a mixture of the following three compounds: 1,3(20),6,10,14-phytapentaene, $\alpha$-springene, and 3,7,11,15-tetramethylhexadeca-1,3,6,10,14-pentaene $(E, E, E)$ (compound 5, 6, and $\mathbf{7}$ in Fig. 6). Considering the structures of these three compounds, the Cyc2 with the DDXXD motif would react with GGDP by ionizationinitiated reaction to an allylic carbocation, followed by deprotonation to the olefin (Fig. 6). Therefore, we expected that Cyc2 might react with other polyprenyl diphosphates, such as FDP (8) and geranyl diphosphate (GDP, 12), which are one and two $\mathrm{C}_{5}$-units shorter than GGDP (1), respectively. When Cyc2 was incubated with FDP (8), new compounds were also detected in a manner similar to that of GGDP. These compounds were purified, and their structures were determined to be three olefinic compounds, which had the same structures as those formed from GGDP, except for the chain-lengths (compounds 9, 10, and $\mathbf{1 1}$ in Fig. 6). On the other hand, GDP (12) was inactive as a substrate.

The kinetic studies of the reactions catalyzed by Cyc2 with TDP (2) (reaction 2), GGDP (1) (reaction 3), and FDP (8) (reaction 4) as the substrates were performed (Table 1). The $K \mathrm{~m}$ values of $\mathrm{Cyc} 2$ were calculated to be $7.6 \pm 0.6 \mu \mathrm{M}$ for TDP (2), 7.9 $\pm 0.6 \mu \mathrm{M}$ for GGDP (1), and $61.7 \pm 3.0 \mu \mathrm{M}$ for $\operatorname{FDP}(\mathbf{8})$, thereby indicating that the enzyme has a higher affinity for $\mathrm{C}_{20}$-substrates than for $\mathrm{C}_{15}$-substrates. The Vmax value of Cyc2 for TDP (2) was 13-fold higher than that for GGDP (1) and 7-fold higher than that for FDP (8). The calculated $V \max / K m$ value of reaction 2 was 15 fold higher than that for reaction 3 and 58-fold higher than that for reaction 4 . These results suggested that the conversion of TDP (2) into TTE (3) was probably a reasonable reaction among those catalyzed by $\mathrm{Cyc} 2$ and that diterpene olefins and sesquiterpene olefins, which were formed by reaction 3 and reaction 4, respectively, were artifacts generated in vitro.

Biological Significance of the Mevalonate Pathway in TP Producers [77]

As described above, actinomycetes possessing only the MEP pathway also produce isoprenoid compounds [68 70], thereby showing that the presence of the MV pathway is not essential for the production of isoprenoids in actinomycetes. To investigate a biological significance, the following two experiments were performed.

First, we examined the temporal expressions of the MV pathway genes and the MEP pathway genes in the TP producer [77]. Following the cloning of a $d x s$ gene and a $d x r$ gene, which participate in the first step and the second step of the MEP pathway, respectively, by PCR, Northern and primer extension analyses were performed. We were able to detect transcripts of the $d x s$ and $d x r$ genes throughout the cultivation (Fig. 7B D). On the other hand, messages of the MV pathway genes were not detected during the early phase of growth but simultaneously appeared at a timing, which coincided with the initiation of TP production (Fig. 7E, F). These results clearly showed that the MEP pathway operated throughout the cell growth and that the MV pathway was transcriptionally regulated to operate during the late phase of growth [77].

Second, in order to determine the ratio of the contribution of the MV and MEP pathways to TP production, we constructed a mutant in which the HMGCoA reductase gene $(h m g r)$ was specifically disrupted by a double-crossing homologous recombination. Although the cell growth of the mutant strain was almost similar to that of the wild type strain, the mutant strain produced approximately $60 \%$ less TP than the wild type strain [77] (Fig. 8), thereby suggesting that the MV pathway supplied $60 \%$ of IPP for TP biosynthesis and that the MEP pathway 
(A)

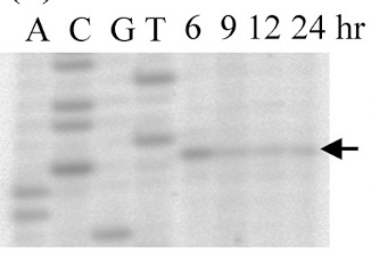

(D)

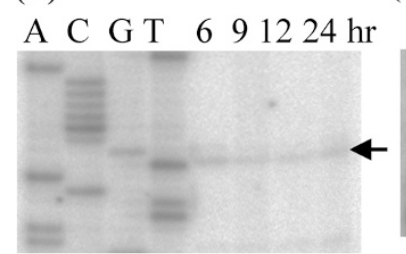

(G)



(B)

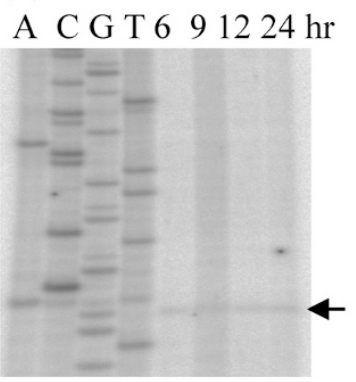

(E)
(C)

A C G T $691224 \mathrm{hr}$

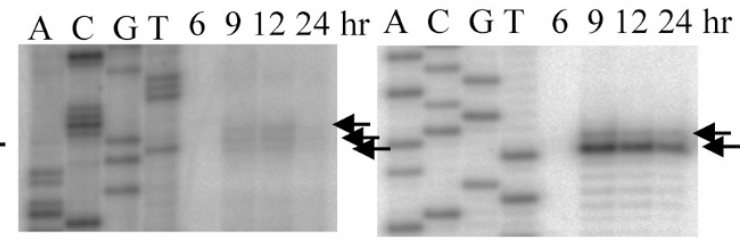

(H)



Fig. 7 Primer extension analysis of the genes participating in the terpenoid biosynthesis (A F). Total RNA was isolated from TP producer grown at $30^{\circ} \mathrm{C}$ for $6,9,12$ and 24 hours, at which cell growth (G) and terpentecin productivity (bioassay, $\mathrm{H})$ were also measured, and subjected to primer extension analysis. Arrows in $(\mathrm{A} \sim \mathrm{F})$ indicate the transcriptional start sites. Alphabet indicate the following genes used as the probes: A, glyceraldehydes 3-phosphate dehydrogenase gene (control); B, 1-deoxy-D-xylulose 5-phosphate synthase 1 (dxs1); C, 1-deoxy-D-xylulose 5-phosphate synthase 2 (dxs2, TP producer has two distinct $d x$ s genes); D, 1-deoxy-D-xylulose 5-phosphate reductoisomerase (dxr); E, GGDP synthase \{ORF1 (GGDP synthase) to 7 (HMG-CoA synthase) in Fig. 6A were confirmed to be polycistronically transcribed by Northern blot analysis\}; TP biosynthetic gene $\{$ P450 (ORF10 in Fig. 6A) .

(A)

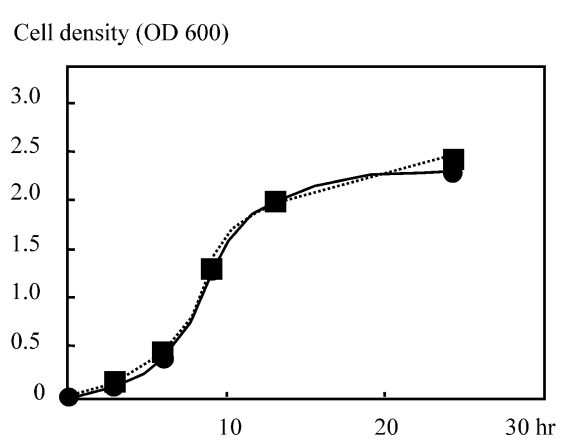

(B)

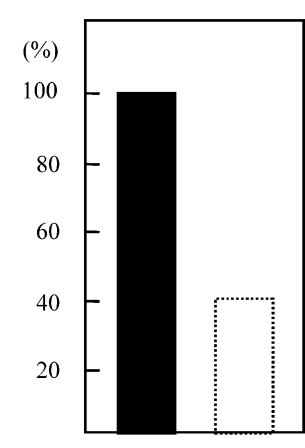

Fig. 8 Cell growth (A) and TP productivity (B) of wild type strain (solid line) and an HMG-CoA disrupted mutant (dotted line). 
contributed $40 \%$.

The Relationship between the MV Pathway Genes and Isoprenoid Biosynthetic Genes in a BE-40644 Producer [78]

As described above, the MV pathway gene cluster was located in the region adjacent to the TP biosynthetic gene cluster [75], and it supplied more than $50 \%$ of the IPP required for TP biosynthesis. These facts led us to investigate whether MV pathway genes and isoprenoid biosynthetic genes are always clustered in strains possessing both the MV and MEP pathways. Therefore, we cloned an MV pathway gene cluster from Actinoplanes sp. strain A40644, an isoprenoid antibiotic BE-40644 producer, expecting that a BE-40644 biosynthetic gene cluster, including an isoprenoid cyclase gene catalyzing a cyclization of FDP-containing linear intermediate, (Fig. 9) would be present in the region adjacent to the MV pathway genes [78].

A DNA region homologous to the HMG-CoA reductase of TP producers was cloned and the nucleotide sequences of the fragment were determined. We detected the same MV pathway genes as those found in naphterpin and TP producers, which contained 6 ORFs from MK to HMGCoA synthase (Fig. 5B). Moreover, a farnesyl diphosphate synthase $\left(\mathrm{C}_{15}\right)$ gene was located at the region just upstream of the MK gene in a manner similar to that in the TP producer. In the TP producer, a GGDP synthase gene that would supply a direct precursor $\left(\mathrm{C}_{20}\right)$ of TP biosynthesis was also located in a region just upstream of the MV pathway gene cluster. Therefore, we expected the presence of the BE-40644 biosynthetic genes in the regions flanked by the MV pathway gene cluster because BE-40644 has a $\mathrm{C}_{15}$ unit. By sequencing analysis of the downstream region, we detected 11 ORFs (Fig. 5B) that would participate in the biosynthesis of BE-40644 (Fig. 9), although we could not find a typical isoprenoid cyclase gene among them.

To determine whether the ORFs found in the downstream region of the MV pathway gene cluster would indeed encode the BE-40644 biosynthetic genes, these genes were expressed in a heterologous host, S. lividans TK23, and the production of BE-46044-related compounds was examined [78]. By using HPLC analysis, a compound that was eluted with almost the same retention time as that

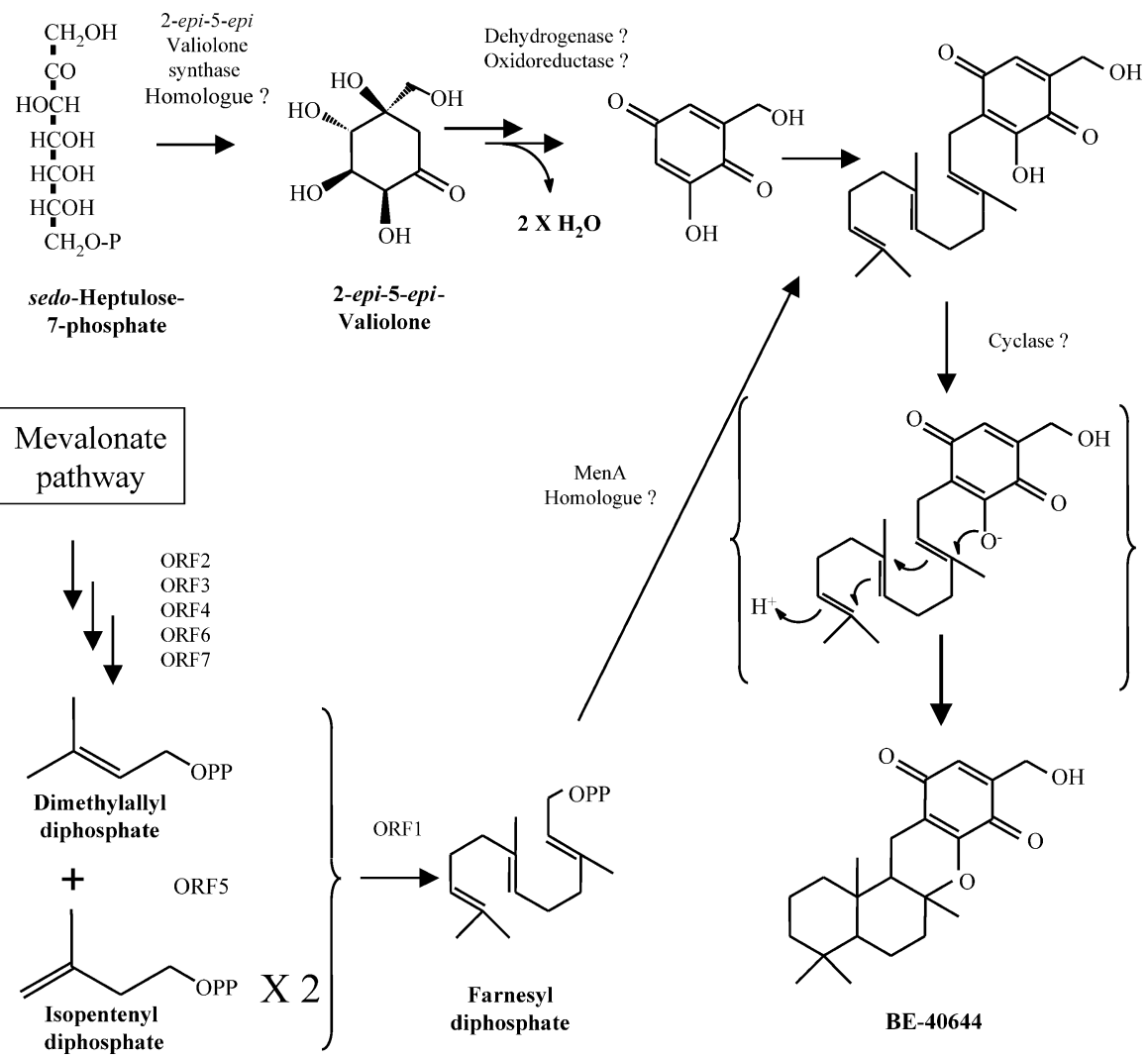

Fig. 9 Proposed biosynthetic pathway of BE-40644. Estimated functions of each ORFs and genes were also added into each biosynthetic step. 
of the authentic BE-40644 was specifically detected in the culture broth of the transformant. The product was purified, and its structure was determined; the product was found to be BE-40644. This result again showed that the MV pathway genes and isoprenoid biosynthetic genes were clustered in an actinomycete strain possessing both the MV and MEP pathways.

As mentioned above, we could not find a typical isoprenoid cyclase gene in the DNA fragment used for the heterologous expression, in spite of the fact that the transformant produced BE-40644, and an isoprenoid cyclase is thought to participate in the biosynthesis of BE40644 (Fig. 9). Considering that S. lividans TK23 is not known to produce BE-40644-related compounds, the hypothetical ORFs in the BE-40644 biosynthetic genes, represented by question marks in Fig. 5B, might participate in a cyclization reaction.

Analyses of the Flanking Regions of Mevalonate Pathway Gene Clusters in a Furaquinocin A Producer [79]

As described above, we showed that gene clusters concerned with the biosyntheses of TP [75] and BE-40644 [78], a diterpene antibiotic and a sesquiterpene antibiotic, respectively, were located in the adjacent MV pathway gene clusters. Next, to examine whether an MV pathway gene cluster and isoprenoid biosynthetic genes are always clustered in all the actinomycete strains possessing both pathways, an MV pathway gene cluster was cloned from Streptomyces sp. strain KO-3988, a furaquinocin A producer, which has naphtoquinone and $\mathrm{C} 10$-isoprenoid moieties (Fig. 4A).

By colony hybridization using the HMG-CoA reductase gene cloned from the TP producer as a probe, we isolated several positive cosmids. Among them, some cosmids contained a $1.6 \mathrm{~kb}$ Bam HI fragment that again hybridized to the probe by Southern hybridization. Interestingly, a $7.2 \mathrm{~kb}$ BamHI fragment in other cosmids also hybridized to the probe, thereby suggesting that strain KO-3988 might have two distinct HMG-CoA reductase genes. Therefore, we determined the nucleotide sequences of the entire MV pathway clusters, including each of the HMG-CoA reductase genes. Finally, we identified two distinct MV pathway gene clusters, both of which involved 6 genes in a manner similar to those found in naphterpin, TP, and BE40644 producers (unpublished results).

First, we analyzed the flanking regions of one of the MV clusters (MV1) and found 4 ORFs that could encode a putative cytochrome P450 (ORF1), a diterpene cyclase
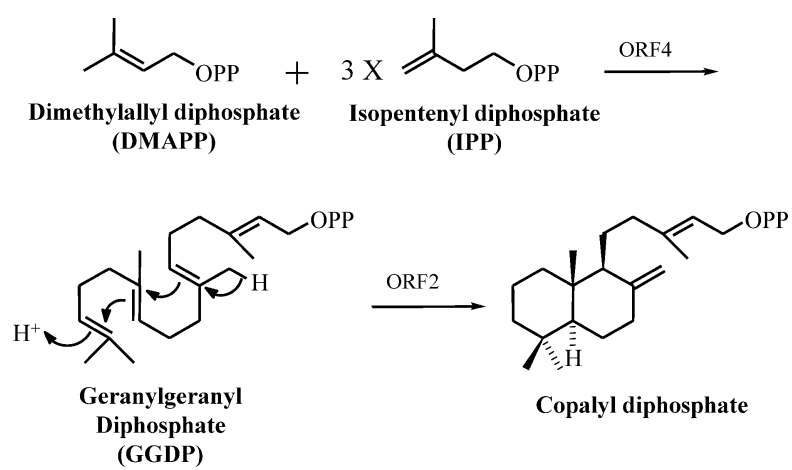

Fig. 10 Biosynthesis of copalyl diphosphate by the ORF2 and ORF4 products.

(ORF2), an unknown protein (ORF3), and a GGDP $\left(\mathrm{C}_{20}\right)$ synthase gene (ORF4) in the upstream region of the MV1 cluster [79] (Fig. 5C), although we did not find genes related to the biosynthesis of furaquinocin $\mathrm{A}$. Considering that the ORF2 product is similar to isoprenoid cyclases with DXDD motifs, it was assumed to convert GGDP into a cyclized intermediate with the diphosphate group by the protonation-initiated cyclization (Fig. 3, B type). To examine this possibility, we overproduced the ORF2 product as a His-tagged recombinant protein, and the purified enzyme was incubated with GGDP. By a reversedphase HPLC analysis using an ion-pair reagent, the formation of a reaction product, which was eluted with a retention time shorter than that of GGDP, was specifically detected. The product was purified, and its structure was determined to be anti-copalyl diphosphate or its enantiomer, ent-copalyl diphosphate, as shown in Fig. 10, although the absolute stereochemistry of the product remains unclear. However, this is the first example of an enzyme of prokaryotic origin with this function [79].

To date, several anti-copalyl diphosphate synthase genes and ent-copalyl diphosphate synthase genes have been cloned from plants and fungi. Therefore, we compared the amino acid sequences of ORF2 with those from eukaryotes. Very interestingly, the protein most homologous to the ORF2 product was Cyc1 (Fig. 11, 36\% identity over 499 amino acids), which was confirmed to catalyze a conversion of GGDP into TDP in TP biosynthesis as described above. Therefore, the ORF2 product would be useful in examining a relationship between amino acid sequences of an isoprenoid cyclase and its product specificity, including stereospecificity. Moreover, Hoshino and co-workers have very recently demonstrated that Mycobacterium tuberculosis H37Rv3377c, which has a significant similarity to the Cyc1 essential for TP biosynthesis, encodes a diterpene cyclase for producing the halimane skeleton [80]. Taken together, isoprenoid cyclases 


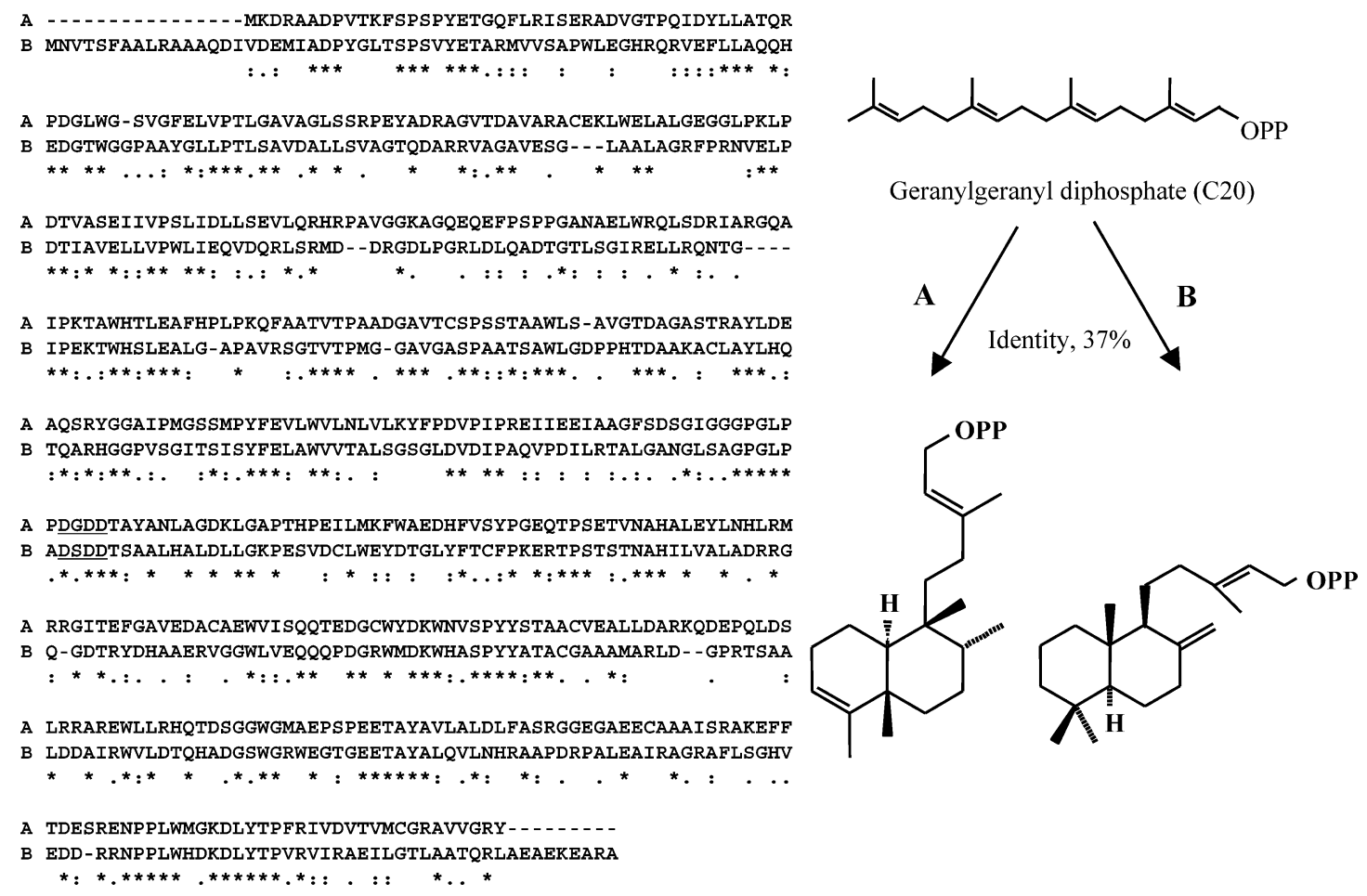

Fig. 11 Alignment of the Cyc1 (A) and the ORF2 (B), which catalyze a conversion of GGDP into terpentedienol diphosphate (TDP) and copalyl diphosphate, respectively. Although both cyclases use GGDP as a substrate, have 37\% amino acid identities and catalyze a cyclization by protonation-initiated, different successive reactions to quench carbocation proceed during cyclization.

found in actinobacteria might have unique primary structures and enzymatic properties that differ from those found in eukaryotes. Therefore, actinomycetes possessing the mevalonate pathway gene clusters might be a treasure house of unique isoprenoid compounds.

With respect to the other MV cluster (MV2) cloned from the furaquinocin A producer, we have recently finished the sequencing analysis of the flanking regions of the cluster and found that putative furaquinocin A biosynthetic genes exist both in the upstream and downstream regions of the cluster (unpublished result). These results again showed that actinomycetes possessing the MV pathway usually produce an isoprenoid and that its biosynthetic gene cluster exists adjacent to the mevalonate pathway gene cluster.

\section{Conclusion}

As exemplified by the $\mathrm{Cyc} 1$ and $\mathrm{Cyc} 2$ genes that participate in the biosynthesis of TP and by the copalyl diphosphate synthase found in the furaquinocin A producer, isoprenoid biosynthetic enzymes found in actinomycete strains have unique primary structures that differ from those of eukaryotes. This fact suggests that isoprenoid compounds produced by actinomycetes would be potent and unique lead compounds for drug discovery. Moreover, based on the analyses of biosynthetic gene clusters of TP, BE-40644, and furaquinocin $\mathrm{A}$, we could develop the following methodology to screen actinomycete strains producing isoprenoid compounds.

All the actinomycete strains possessing both the MV and MEP pathways for the formation of IPP always produce isoprenoid compounds, and biosynthetic genes of one of these isoprenoids always exist adjacent to the MV pathway gene cluster. Currently, detection of the presence of the MV pathway genes can be easily accomplished by PCR and hybridization. Therefore, when the presence of the MV cluster is detected by molecular genetic techniques, isoprenoids may be produced by the cultivation of these actinomycete strains.

Acknowledgments We thank Dr. M. Hamada of Institute of Microbial Chemistry, Prof. S. Ōmura of Kitasato Institute and Banyu Pharmaceutical Co., Ltd. for providing us with the producing microorganism of terpentecin, furaquinocin A and BE40644. All of these studies were carried out at my laboratory together with several students, especially by Dr. Y. Hamano (TP biosynthesis) and Dr. T. Kawasaki (BE-40644 and copalyl 
diphosphate biosyntheses). I am also grateful my colleagues especially to Prof. H. Seto of Tokyo University of Agriculture, Profs. T. Kuzuyama and K. Furihata of The University of Tokyo who performed these experiments in collaboration. Theses works were supported in part by a Grant-in-aid for Scientific Research (B and C), the Naito Foundation, the Uehara Memorial Foundation, and the Novozymes Research Foundation to T. Dairi.

\section{References}

1. Miyadoh S. Research on antibiotic screening in Japan over the last decade. Actinomycetologica 7: 100-106 (1993)

2. Walsh CT. Polyketide and nonribosomal peptide antibiotics: modularity and versatility. Science 303: 1805-1810 (2004)

3. Mijts BN, Schmidt-Dannert C. Engineering of secondary metabolite pathways. Curr Opin Biotechnol 14: 597-602 (2003)

4. Weber T, Welzel K, Pelzer S, Vente A, Wohlleben W. Exploiting the genetic potential of polyketide producing streptomycetes. J Biotechnol 106: 221-232 (2003)

5. Shen B. Polyketide biosynthesis beyond the type I, II and III polyketide synthase paradigms. Curr Opin Chem Biol 7: 285-295 (2003)

6. Liou GF, Khosla C. Building-block selectivity of polyketide synthases. Curr Opin Chem Biol 7: 279-284 (2003)

7. Ikeda H, Nonomiya $\mathrm{T}$, Usami M, Ohta $\mathrm{T}$, Ōmura S. Organization of the biosynthetic gene cluster for the polyketide anthelmintic macrolide avermectin in Streptomyces avermitilis. Proc Natl Acad Sci USA 96: 9509-9514 (1999)

8. Chappell J. Biochemistry and molecular biology of the isoprenoid biosynthetic pathways in plants. Ann Rev Plant Physiol Plant Mol Biol 46: 521-547 (1995)

9. Macmillan J, Beale MH. Diterpene biosynthesis. In: Comprehensive Natural Products Chemistry, Vol. 2. Elsevier, Oxford, pp. 217-243 (1999)

10. Cane DE, Sohng JK, Lamberson CR, Rudnicki SM, Wu Z, Lloyd MD, Oliver JS, Hubbard BR. Pentalenene synthase. Purification, molecular cloning, sequencing, and high-level expression in Escherichia coli of a terpenoid cyclase from Streptomyces UC5319. Biochemistry 33: 5846-5857 (1994)

11. Cane DE, Rosshi T, Pachlatko JP. The biosynthesis of pentalenolactone. Tetrahedron Lett 20: 3639-3642 (1979)

12. Tamamura T, Sawa T, Isshiki K, Masuda T, Homma Y, Inuma $H$, Naganawa $H$, Hamada M, Takeuchi T, Umezawa H. Isolation and characterization of terpentecin, a new antitumor antibiotic. J Antibiot 38: 1664-1669 (1985)

13. Shiomi K, Nakamura H, Inuma H, Naganawa H, Isshiki K, Takeuchi T, Umezawa H, Iitaka Y. Structures of new antibiotics napyradiomycins. J Antibiot 39: 494-501 (1986)

14. Shin-ya K, Imai S, Furihata K, Hayakawa Y, Kato Y, Vanduyne GD, Clardy J, Seto H. Isolation and structural elucidation of an antioxidative agent, naphterpin. J Antibiot
43: 444-447 (1990)

15. Nakanishi S, Osawa K, Saito Y, Kawamoto I, Kuroda K, Kase H. KS-505a, a novel inhibitor of bovine brain $\mathrm{Ca}^{2+}$ and calmodulin-dependent cyclic-nucleotide phosphodiesterase from Streptomyces argenteolus. J Antibiot 45: 341-347 (1992)

16. Komiyama K, Funayama S, Anraku Y, Ishibashi M, Takahashi Y, Ōmura S. Novel antibiot, furaquinocins A and B. Taxonomy, fermentation, isolation and physico-chemical and biological characteristics. J Antibiot 43: 247-252 (1990)

17. Torigoe K, Wakasugi N, Sakaizumi N, Ikejima T, Suzuki H, Kojiri K, Suda H. BE-40644, a new human thioredoxin system inhibitor isolated from Actinoplanes sp. A40644. J Antibiot 49: 314-317 (1996)

18. Komaki H, Nemoto A, Tanaka Y, Takagi H, Yazawa K, Mikami Y, Shigemori H, Kobayashi J, Ando A, Nagata Y. Brasilicardin A, a new terpenoid antibiotic from pathogenic Nocardia brasiliensis: fermentation, isolation and biological activity. J Antibiot 52: 13-19 (1999)

19. Kuzuyama T, Seto H. Diversity of the biosynthesis of the isoprene units. Nat Prod Rep 20: 171-183 (2003)

20. Bohlmann J, Meyer-Gauen, Croteau R. Plant terpenoid synthases: Molecular biology and phylogenetic analysis. Proc Natl Acad Sci USA 95: 4126-4133 (1998)

21. Lees ND, Skaggs B, Kirsch DR, Bard M. Cloning of the late genes in the ergosterol biosynthetic pathway of Saccharomyces cerevisiae - a review. Lipids 30: 221-226 (1995)

22. Haralampidis K, Trojanowska M, Osbourn AE. Biosynthesis of triterpenoid saponins in plants. Adv Biochem Eng Biotechnol 75: 31-49 (2002)

23. Hoshino T, Sato T. Squalene-hopene cyclase: catalytic mechanism and substrate recognition. Chem Commun 21: 291-301 (2002)

24. Poralla K. Profound insights into squalene cyclization. Chem Biol 11: 12-14 (2004)

25. Bohlmann L, Steele CL, Croteau R. Monoterpene synthases from grand fir (Abies grandis). cDNA isolation, characterization, and functional expression of myrcene synthase, (-)-(4S)-limonene synthase, and (-)-(1S,5S)pinene synthase. J Biol Chem 272: 21784-21792 (1997)

26. Bohlmann L, Phillips M, Ramachandiran V, Katoh S, Croteau R. cDNA cloning, characterization, and functional expression of four new monoterpene synthase members of the Tpsd gene family from grand fir (Abies grandis). Arch Biochem Biophys 368: 232-243 (1999)

27. Steele CL, Crock J, Bohlmann J, Croteau R. Sesquiterpene synthases from grand fir (Abies grandis). Comparison of constitutive and wound-induced activities, and cDNA isolation, characterization, and bacterial expression of deltaselinene synthase and gamma-humulene synthase. J Biol Chem 273: 2078-2089 (1998)

28. Bohlmann J, Crock J, Jetter R, Croteau R. Terpenoid-based defenses in conifers: cDNA cloning, characterization, and functional expression of wound-inducible $(E)$-alpha- 
bisabolene synthase from grand fir (Abies grandis). Proc Natl Acad Sci USA 95: 6756-6761 (1998)

29. Vogel BS, Wildung MR, Vogel G, Croteau R. Abietadiene synthase from grand fir (Abies grandis). cDNA isolation, characterization, and bacterial expression of a bifunctional diterpene cyclase involved in resin acid biosynthesis. J Biol Chem 271: 23262-23268 (1996)

30. Wildung MR, Croteau R. A cDNA clone for taxadiene synthase, the diterpene cyclase that catalyzes the committed step of taxol biosynthesis. J Biol Chem 271: 9201-9204 (1996)

31. Mau CJ, West CA. Cloning of casbene synthase cDNA: evidence for conserved structural features among terpenoid cyclases in plants. Proc Natl Acad Sci USA 91: 8497-8501 (1994)

32. Faldt J, Martin D, Miller B, Rawat S, Bohlmann J. Traumatic resin defense in Norway spruce (Picea abies): methyl jasmonate-induced terpene synthase gene expression, and cDNA cloning and functional characterization of (+)-3carene synthase. J Plant Mol Biol 51: 119-133 (2003)

33. Martin DM, Faldt J, Bohlmann J. Functional characterization of nine Norway Spruce TPS genes and evolution of gymnosperm terpene synthases of the TPS-d subfamily. Plant Physiol 135: 1908-1927 (2004)

34. Schnee C, Kollner TG, Gershenzon J, Degenhardt J. The maize gene terpene synthase 1 encodes a sesquiterpene synthase catalyzing the formation of $(E)$-beta-farnesene, $(E)$-nerolidol, and $(E, E)$-farnesol after herbivore damage. Plant Physiol 130: 2049-2060 (2002)

35. Degenhardt J, Gershenzon J. Demonstration and characterization of $(E)$-nerolidol synthase from maize: a herbivore-inducible terpene synthase participating in $(3 E)$ 4,8-dimethyl-1,3,7-nonatriene biosynthesis. Planta 210: 815-822 (2000)

36. Kollner J, Schnee C, Gershenzon J, Degenhardt J. The variability of sesquiterpenes emitted from two Zea mays cultivars is controlled by allelic variation of two terpene synthase genes encoding stereoselective multiple product enzymes. Plant Cell 16: 1115-1131 (2004)

37. Phillips MA, Wildung MR, Williams DC, Hyatt DC, Croteau R. cDNA isolation, functional expression, and characterization of (+)-alpha-pinene synthase and (-)alpha-pinene synthase from loblolly pine (Pinus taeda): stereocontrol in pinene biosynthesis. Arch Biochem Biophys 411: 267-276 (2003)

38. Schepmann HG, Pang J, Matsuda SP. Cloning and characterization of Ginkgo biloba levopimaradiene synthase which catalyzes the first committed step in ginkgolide biosynthesis. Arch Biochem Biophys 392: 263-269 (2001)

39. Dudareva N, Martin D, Kish CM, Kolosova N, Gorenstein N, Faldt J, Miller B, Bohlmann J. (E)-beta-ocimene and myrcene synthase genes of floral scent biosynthesis in snapdragon: function and expression of three terpene synthase genes of a new terpene synthase subfamily. Plant Cell 15: 1227-1241 (2003)
40. Lucker J, Bowen P, Bohlmann J. Vitis vinifera terpenoid cyclases: functional identification of two sesquiterpene synthase cDNAs encoding (+)-valencene synthase and (-)germacrene D synthase and expression of mono- and sesquiterpene synthases in grapevine flowers and berries. Phytochemistry 65: 2649-2659 (2004)

41. Arimura G, Ozawa R, Kugimiya S, Takabatashi J, Bohlmann J. Herbivore-induced defense response in a model legume. Two-spotted spider mites induce emission of $(E)$-betaocimene and transcript accumulation of $(E)$-beta-ocimene synthase in Lotus japonicus. Plant Physiol 135: 1976-1983 (2004)

42. Bohlmann J, Stauber EJ, Krock B, Oldham NJ, Gershenzon J, Baldwin IT. Gene expression of 5-epi-aristolochene synthase and formation of capsidiol in roots of Nicotiana attenuata and N. sylvestris. Phytochemistry 60: 109-116 (2002)

43. Bohlmann J, Martin D, Oldham NJ, Gershenzon J. Terpenoid secondary metabolism in Arabidopsis thaliana: cDNA cloning, characterization, and functional expression of a myrcene/(E)-beta-ocimene synthase. Arch Biochem Biophys 375: 261-269 (2000)

44. Chen F, Tholl D, D'Auria JC, Farooq A, Pichersky E, Gershenzon J. Biosynthesis and emission of terpenoid volatiles from Arabidopsis flowers. Plant Cell 15: 481-494 (2003)

45. Faldt J, Arimura G, Gershenzon J, Takabayashi J, Bohlmann J. Functional identification of AtTPS03 as (E)-beta-ocimene synthase: a monoterpene synthase catalyzing jasmonate- and wound-induced volatile formation in Arabidopsis thaliana. Planta 216: 745-751 (2003)

46. Chen F, Ro DK, Petri J, Gershenzon J, Bohlmann J, Pichersky E, Tholl D. Characterization of a root-specific Arabidopsis terpene synthase responsible for the formation of the volatile monoterpene 1,8-cineole. Plant Physiol 135: 1956-1966 (2004)

47. Sun TP, Kamiya Y. The Arabidopsis GA1 locus encodes the cyclase ent-kaurene synthetase A of gibberellin biosynthesis. Plant Cell 6: 1509-1518 (1994)

48. Yamaguchi S, Saito T, Abe H, Yamane H, Murofushi N, Kamiya Y. Molecular cloning and characterization of a cDNA encoding the gibberellin biosynthetic enzyme entkaurene synthase B from pumpkin (Cucurbita maxima L.). Plant J 10: 203-213 (1996)

49. Kawaide H, Imai R, Sassa T, Kamiya Y. Ent-kaurene synthase from the fungus Phaeosphaeria sp. L487. cDNA isolation, characterization, and bacterial expression of a bifunctional diterpene cyclase in fungal gibberellin biosynthesis. J Biol Chem 272: 21706-21712 (1997)

50. Yamaguchi S, Kamiya Y. Gibberellin biosynthesis: its regulation by endogenous and environmental signals. Plant Cell Physiol 41: 251-257 (2000)

51. Hedden P, Phillips AL, Rojas MC, Carrera E, Tudzynski B. Gibberellin biosynthesis in plants and fungi: A case of convergent evolution? J Plant Growth Regul 20: 319-331 
(2002)

52. Cho EM, Okada A, Kenmoku H, Otomo K, Toyomasu T, Mitsuhashi W, Sassa T, Yajima A, Yabuta G, Mori K, Oikawa H, Toshima H, Shibuya N, Nojiri H, Omori T, Nishiyama M, Yamane H. Molecular cloning and characterization of a cDNA encoding ent-cassa-12,15-diene synthase, a putative diterpenoid phytoalexin biosynthetic enzyme, from suspension-cultured rice cells treated with a chitin elicitor. Plant J 37: 1-8 (2004)

53. $\mathrm{Xu} \mathrm{M}$, Hillwig ML, Prisic S, Coates RM, Peters RJ. Functional identification of rice syn-copalyl diphosphate synthase and its role in initiating biosynthesis of diterpenoid phytoalexin/allelopathic natural products. Plant J 39: 309 318 (2004)

54. Wilderman PR, Xu M, Jin Y, Coates RM, Peters RJ. Identification of syn-pimara-7,15-diene synthase reveals functional clustering of terpene synthases involved in rice phytoalexin/allelochemical biosynthesis. Plant Physiol 135: 2098-2105 (2004)

55. Otomo K, Kenmoku H, Oikawa H, Konig WA, Toshima H, Mitsuhashi W, Yamane H, Sassa T, Toyomasu T. Biological functions of ent-and syn-copalyl diphosphate synthases in rice: Key enzymes for the branch point of gibberellin and phytoalexin biosynthesis. Plant J 39: 886-893 (2004)

56. Otomo K, Kanno Y, Motegi A, Kenmoku H, Yamane H, Mitsuhashi W, Oikawa H, Toshima H, Itoh H, Matsuoka M, Sassa T, Toyomasu T. Diterpene cyclases responsible for the biosynthesis of phytoalexins, momilactones $\mathrm{A}, \mathrm{B}$, and oryzalexins $\mathrm{A} \sim \mathrm{F}$ in rice. Biosci Biotechnol Biochem 68: 2001-2006 (2004)

57. Nemoto T, Cho EM, Okada A, Okada K, Otomo K, Kanno Y, Toyomasu T, Mitsuhashi W, Sassa T, Minami E, Shibuya N, Nishiyama M, Nojiri H, Yamane H. Stemar-13-ene synthase, a diterpene cyclase involved in the biosynthesis of the phytoalexin oryzalexin $\mathrm{S}$ in rice. FEBS Lett 571: 182-186 (2004)

58. Sakamoto T, Miura K, Itoh H, Tatsumi T, Ueguchi-Tanaka M, Ishiyama K, Kobayashi M, Agrawal GK, Takeda S, Abe K, Miyao A, Hirochika H, Kitano H, Ashikari M, Matsuoka M. An overview of gibberellin metabolism enzyme genes and their related mutants in rice. Plant Physiol 134: 1642-1653 (2004)

59. Proctor RH, Hohn TM. Aristolochene synthase. Isolation, characterization, and bacterial expression of a sesquiterpenoid biosynthetic gene (Ari1) from Penicillium roqueforti. J Biol Chem 268: 4543-4548 (1993)

60. Oikawa H, Toyomasu T, Toshima H, Ohashi S, Kawaide H, Kamiya Y, Ohtsuka M, Shinoda S, Mitsuhashi W, Sassa T. Cloning and functional expression of cDNA encoding aphidicolan-16 beta-ol synthase: A key enzyme responsible for formation of an unusual diterpene skeleton in biosynthesis of aphidicolin. J Am Chem Soc 123: 51545145 (2001)

61. Tudzynski B, Kawaide H, Kamiya Y. Gibberellin biosynthesis in Gibberella fujikuroi: cloning and characterization of the copalyl diphosphate synthase gene. Curr Genet 34: 234-240 (1998)

62. Cane DE, Watt RM. Expression and mechanistic analysis of a germacradienol synthase from Streptomyces coelicolor implicated in geosmin biosynthesis. Proc Natl Acad Sci USA 100: 1547-1551 (2003)

63. Isshiki K, Tamamura T, Sawa T, Naganawa H, Takeuchi T, Umezawa H. Biosynthetic studies of terpentecin. J Antibiot 39: 1634-1635 (1986)

64. Seto H, Orihata N, Furihata K. Studies on the biosynthesis of terpenoids produced by actinomycetes. Part 4 . Formation of BE-40644 by the mevalonate and nonmevalonate pathways. Tetrahedron Lett 39: 9497-9500 (1998)

65. Seto H, Watanabe H, Furihata K. Simultaneous operation of the mevalonate and non-mevalonate pathways in the biosynthesis of isopentenyl diphosphate in Streptomyces aeriouvifer. Tetrahedron Lett 37: 7979-7982 (1996)

66. Funayama S, Ishibashi M, Komiyama K, Ōmura S. Biosynthesis of furaquinocins A and B. J Org Chem 55: 1132-1133 (1990)

67. Shimoi K, Iinuma H, Naganawa H, Isshiki K, Takeuchi T, Umezawa H. Biosynthesis of napyradiomycins. J Antibiot 40: 1740-1745 (1987)

68. Cane DE, Rosshi T, Pachlatko JP. The biosynthesis of pentalenolactone. Tetrahedron Lett 20: 3639-3642 (1979)

69. Shigemori H, Komaki H, Yazawa K, Mikami Y, Nemoto A, Tanaka Y, Kobayashi J. Biosynthesis of diterpenoid moiety of brasilicardin A via non-mevalonate pathway in Nocardia brasiliensis. Tetrahedron Lett 40: 4353-4354 (1999)

70. Seto H, Watanabe H, Orihata N, Furihata K. Abstracts of 38th Symposium on the Chemistry of Natural Products, Sendai, 1996, p. 19.

71. Dairi T, Motohira Y, Kuzuyama T, Takahashi S, Itoh N, Seto H. Cloning of the gene encoding 3-hydroxy-3methylglutaryl coenzyme A reductase from terpenoid antibiot-producing Streptomyces strains. Mol Gen Genet 262: 957-964 (2000)

72. Takahashi S, Kuzuyama T, Seto H. Purification, characterization, and cloning of a eubacterial 3-hydroxy-3methylglutaryl coenzyme A reductase, a key enzyme involved in biosynthesis of terpenoids. J Bacteriol 181: 1256-1263 (1999)

73. Takagi M, Kuzuyama T, Takahashi S, Seto H. A gene cluster for the mevalonate pathway from Streptomyces sp. strain CL190. J Bacteriol 182: 4153-4157 (2000)

74. Hamano Y, Dairi T, Yamamoto M, Kawasaki T, Kaneda K, Kuzuyama T, Itoh N, Seto H. Cloning of a gene cluster encoding enzymes responsible for the mevalonate pathway from a terpenoid-antibiotic-producing Streptomyces strain. Biosci Biotechnol Biochem 65: 1627-1635 (2001)

75. Dairi T, Hamano Y, Kuzuyama T, Itoh N, Furihata K, Seto H. Eubacterial diterpene cyclase genes essential for production of isoprenoid antibiotic-terpentecin. J Bacteriol 183: 6085-6094 (2001)

76. Hamano Y, Kuzuyama T, Itoh N, Furihata K, Seto H, Dairi 
T. Functional analysis of eubacterial diterpene cyclases responsible for biosynthesis of a diterpene antibioticterpentecin. J Biol Chem 277: 37098-37104 (2002)

77. Hamano Y, Dairi T, Yamamoto M, Kuzuyama T, Itoh N, Seto H. Growth phase dependent expression of the mevalonate pathway in a terpenoid antibiotic-producing Streptomyces strain. Biosci Biotechnol Biochem 66: 808819 (2002)

78. Kawasaki T, Kuzuyama T, Furihata K, Itoh N, Seto H, Dairi T. A relationship between the mevalonate pathway and isoprenoid production in actinomycetes. J Antibiot 56: 957-966 (2003)
79. Kawasaki T, Kuzuyama T, Kuwamori Y, Matsuura N, Itoh N, Furihata K, Seto H, Dairi T. Presence of copalyl diphosphate synthase gene in an actinomycete possessing the mevalonate pathway. J Antibiot 57: 739-747 (2004)

80. Nakano C, Okamura T, Sato T, Dairi T, Hoshino T. Mycobacterium tuberculosis $\mathrm{H} 37 \mathrm{Rv} 3377 \mathrm{c}$ encodes the diterpene cyclase for producing halimane skeleton. Chem Commun 8: 1016-1018 (2005)

81. Kuzuyama T, Takahashi S, Dairi T, Seto H. Detection of the mevalonate pathway in Streptomyces species using the 3hydroxy-3-methylglutaryl coenzyme A reductase gene. J Antibiot 55: 919-923 (2002) 